\title{
Como a tecnologia através da internet torna-se uma alternativa significativa e imprescindível para educação, durante o período da pandemia do COVID-19
}

\author{
How technology through the internet becomes a significant and essential alternative for education
} during the period of the COVID-19 pandemic

Cómo la tecnología a través de Internet se convierte en una alternativa importante y esencial para la educación durante el período de la pandemia COVID-19 E-mail: osmildosobral@gmail.br

Jose Flavio Messias

ORCID: https://orcid.org/0000-0003-1871-7002 Centro Universitário ENIAC, Brasil e-mail: jflaviomessias@ hotmail.com

Gisele Bianchini

ORCID: https://orcid.org/0000-0002-5957-926X Universidade Federal do Paraná, Brasil E-mail: giselebianchini2017@gmail.com

Douglas Leonardo de Lima

ORCID: https://orcid.org/0000-0002-3868-1222 Faculdade de Tecnologia de Mauá, Brasil E-mail: douglas.lima20@uni9.edu.br

Marcos de Oliveira Morais

ORCID: https://orcid.org/0000-0002-5981-4725 Universidade Estácio de Sá, Brasil E-mail: marcostecnologia@ig.com.br

Michele Maria Silva Franco

ORCID: https://orcid.org/0000-0002-2969-0223 Centro Universitário Campo Limpo Paulista, Brasil

E-mail: michele.franco@faccamp.br

Djalma Donizetti Clariano da Silva

ORCID: https://orcid.org/0000-0002-6679-5542 Universidade Guarulhos, Brasil E-mail: djalmaarcca@msn.com

\begin{abstract}
Resumo
Este artigo tem o objetivo abordar como a tecnologia através da Internet, torna-se alternativa significativa e imprescindível para educação, durante o período da pandemia. Os procedimentos metodológicos estão embasados no levantamento de informações através de pesquisas bibliográficas, publicações online como revistas, jornais, legislação e a busca de dados em relatórios virtuais de instituições renomadas na área da saúde e educação. O impacto da pandemia na educação, traz à tona a discussão sobre a urgência de mecanismos para a implementação da educação à distância em nosso país. A tecnologia é um fator primordial no que diz respeito à evolução digital, permitindo experiências proveitosas especificamente no âmbito educacional. Assim, professores e alunos tiveram que se adaptar às aulas a distância e utilizar toda criatividade para dar continuidade às atividades escolares, utilizando para isso a Rede Mundial de Computadores (Internet) a qual foi um diferencial essencial neste processo juntamente com os diversos recursos tecnológicos disponíveis para continuidade do processo de educação das pessoas. Nas conclusões, indica da importância que os países precisam pensar na não dependência de apenas um canal único de aprendizagem à distância para alcançar a todos. Expandir o acesso à Internet e outras soluções digitais para todos os alunos seria uma das principais prioridades de longo prazo para reduzir as vulnerabilidades de aprendizagem. Como resultado verificou-se que a reabertura de escolas e universidades trará benefícios inquestionáveis para os alunos e para a economia em geral, trará benefícios econômicos para as famílias permitindo que alguns pais voltem ao trabalho.
\end{abstract}

Palavras-chave: Pandemia; Isolamento social; Educação; Aprendizagem; Tecnologia; Professores. 


\begin{abstract}
This article aims to address how technology through the Internet becomes a significant and essential alternative for education during the pandemic period. The methodological procedures are based on gathering information through bibliographic research, online publications such as magazines, newspapers, legislation and the search for data in virtual reports from renowned institutions in the area of health and education. The impact of the pandemic on education brings up the discussion about the urgency of mechanisms for the implementation of distance education in our country. Technology is a key factor when it comes to digital evolution, allowing for fruitful experiences specifically in the educational field. Thus, teachers and students had to adapt to distance classes and use all their creativity to continue school activities, using for this the World Wide Web (Internet) which was an essential differential in this process along with the various technological resources available to continue the process of educating people. In the conclusions, it indicates the importance that countries need to think about not depending on a single distance learning channel to reach everyone. Expanding access to the Internet and other digital solutions to all students would be a top long-term priority for reducing learning vulnerabilities. As a result, it was found that the reopening of schools and universities will bring unquestionable benefits for students and for the economy in general, will bring economic benefits for families, allowing some parents to return to work.
\end{abstract}

Keywords: Pandemic; Social isolation; Education; Learning; Technology; Teachers.

\title{
Resumen
}

Este artículo tiene como objetivo abordar cómo la tecnología a través de Internet se convierte en una alternativa importante y esencial para la educación durante el período de la pandemia. Los procedimientos metodológicos se basan en la recopilación de información a través de la investigación bibliográfica, publicaciones en línea como revistas, periódicos, legislación y la búsqueda de datos en informes virtuales de instituciones de renombre en el área de la salud y la educación. El impacto de la pandemia en la educación plantea la discusión sobre la urgencia de los mecanismos para la implementación de la educación a distancia en nuestro país. La tecnología es un factor clave en la evolución digital, permitiendo experiencias fructíferas específicamente en el ámbito educativo. Así, docentes y alumnos debieron adaptarse a las clases a distancia y utilizar toda su creatividad para continuar con las actividades escolares, utilizando para ello la World Wide Web (Internet) que fue un diferencial esencial en este proceso junto con los diversos recursos tecnológicos disponibles para continuar el proceso. de educar a la gente. En las conclusiones, indica la importancia que los países deben pensar en no depender de un único canal de educación a distancia para llegar a todos. Ampliar el acceso a Internet y otras soluciones digitales para todos los estudiantes sería una de las principales prioridades a largo plazo para reducir las vulnerabilidades del aprendizaje. Como resultado, se encontró que la reapertura de escuelas y universidades traerá beneficios indiscutibles para los estudiantes y para la economía en general, traerá beneficios económicos para las familias, permitiendo que algunos padres vuelvan al trabajo.

Palabras clave: Pandemia; Aislamiento social; Educación; Aprendiendo; Tecnología; Maestros.

\section{Introdução}

O presente artigo aborda como a tecnologia através da Internet, torna-se uma alternativa significativa e imprescindível para educação, durante o período de pandemia.

O COVID-19 resultou no fechamento de escolas em todo o mundo. Globalmente, mais de 1,2 bilhão de alunos estão fora da sala de aula.

Como resultado, a educação mudou drasticamente, com o surgimento distinto da educação online, em que o ensino é realizado remotamente e em plataformas digitais.

A pandemia de COVID 19 criou uma crise nos sistemas educacionais como nunca antes vista. Praticamente em todos os países, as escolas fecharam (ou o início do ano letivo foi adiado), portanto, a maioria dos alunos não está frequentando aulas presenciais. Embora a situação ainda seja incerta, na maioria dos casos, o fechamento das escolas foi anunciado até o final de abril. Dependendo de como a situação de saúde progride, o fechamento pode precisar ser estendido por ainda mais tempo.

Esta situação generalizada de "estresse educacional" provavelmente terá impactos negativos sobre os resultados da aprendizagem, visto que nenhum país está adequadamente preparado para mudar para a educação virtual em grande escala como um substituto para a educação tradicional presencial.

Uma grande preocupação é a exacerbação da desigualdade educacional, uma vez que as crianças de famílias de baixa renda terão menos probabilidade de ter os recursos necessários para aproveitar as oportunidades limitadas de educação virtual.

Ao mesmo tempo, o fechamento prolongado de escolas terá efeitos prejudiciais sobre a disponibilidade de alimentos 
em famílias com recursos limitados, onde as escolas geralmente fornecem nutrição suplementar e assistência por meio de programas de alimentação. Em primeiro lugar, as autoridades educacionais - além de liderar os esforços para garantir a continuidade da aprendizagem virtual - devem utilizar seu papel essencial como reguladores para desenvolver e comunicar com eficácia as diretrizes estratégicas para a comunidade educacional como um todo.

Dada à situação em constante mudança, famílias, alunos e professores precisam saber o que se espera deles e sob quais critérios básicos devem operar. Informações críticas como a duração do fechamento de escolas e os padrões para graduação, promoção de série, notas e exames devem ser comunicadas de forma clara e transparente para evitar confusão e fornecer orientação a todos os membros da comunidade educacional.

Os procedimentos metodológicos estão embasados no levantamento de informações através de pesquisas bibliográficas em publicações online como revistas, jornais, legislação e a busca de dados em relatórios virtuais de instituições renomadas na área da saúde e educação

A pesquisa sugere que o aprendizado online aumenta a retenção de informações e leva menos tempo, o que significa que as mudanças que o Corona Vírus causou podem estar aqui para ficar.

\section{Referencial Teórico}

Nas seções seguintes, são apresentados os elementos conceituais necessários ou correlatos ao método proposto. Serão tratados os temas: Como o setor de educação está respondendo ao Covid-19; Impacto cobiçoso na educação; Os desafios da aprendizagem online; O aprendizado online e sua eficácia; A importância da disseminação do conhecimento é destacada por meio do Covid-19; Impacto do Covid-19 na pesquisa em andamento; Impactos na educação: escolas; Impactos na educação: famílias; Ciência aberta é fundamental para a luta contra Covid-19; Ciência aberta responsável; A geração z está tendo uma experiência educacional diferente de qualquer outra geração; Educação escolar em casa; Bloqueio da Covid-19: impacto da pandemia global no setor de educação; Desigualdade entre crianças trazida à tona; Falta de prontidão e infraestrutura para professores.

\subsection{O setor de educação e a responda ao Covid-19}

Segundo Lévy (1999) assinala que seres humanos, pessoas daqui e de toda parte, vocês que são arrastados no grande movimento da desterritorialização. Vocês que pensam reunidos e dispersos entre o hiper córtex das nações, vocês que vivem capturados, esquartejados, nesse imenso acontecimento do mundo que não cessa de voltar a si e de recriarem-se, vocês que são jogados vivos no virtual, vocês que são pegos nesse enorme salto que nossa espécie efetua em direção à nascente do fluxo do ser, sim, no núcleo mesmo desse estranho turbilhão, vocês estão em sua casa. Bem-vindos à nova morada do gênero humano. Bem-vindos aos caminhos do virtual! (Ibidem, 1999)

Cani et al. (2020) esclarecem que diante da nova realidade imposta pela Covid-19, cabe questionarmos não somente acerca do acesso às tecnologias, mas, sobretudo, da possibilidade de serem ofertadas a professores e alunos condições para uso pleno dos recursos tecnológicos, de modo a favorecer uma aprendizagem interativa e colaborativa. Sabemos que são muitos os desafios e os fatores implicados, desde a falta de estrutura tecnológica das escolas, formação dos próprios professores e alunos para um uso crítico das tecnologias.

Couto, Couto e Cruz (2020) indicam que gestores, professores, pais e alunos, desenvolvem outros esquemas para garantir o trabalho e o estudo remotos, para ampliar os limites das escolas por meio de atividades online. Mesmo diante da precária inclusão digital no Brasil e das desconfianças de muitos, a Internet se tornou a tecnologia interativa por meio da qual, de muitas e criativas maneiras, milhares de crianças, jovens e adultos continuaram e continuam a ensinar e aprender nesses tempos conturbados. 


\subsection{Impacto cobiçoso na educação}

Por sorte, o impacto positivo comum aos três grupos de docentes foi a aprendizagem de novas ferramentas tecnológicas e estratégias pedagógicas evidenciando os apontamentos de Barreto e Rocha (2020).

Em meio a esse contexto de educação remota, cabe a todos os envolvidos no processo educacional unir esforços para refletir sobre as estratégias pedagógicas mais adequadas às diversas realidades, a fim de que os impactos e as consequências da pandemia sejam, ao menos, atenuados (Oliveira e Souza, 2020).

Segundo Organização Mundial da Saúde (OMS) (2020), (WHO, on-line), o cenário modificou-se, especialmente em função das recomendações no que se refere ao distanciamento físico, medida essencial para achatamento da curva, ou seja, para diminuir a velocidade de contágio, possibilitando o cuidado, pelos sistemas de saúde, a um maior número de pessoas infectadas.

A modalidade educacional na qual a mediação didático-pedagógica nos processos de ensino e aprendizagem ocorra com a utilização de meios e tecnologias de informação e comunicação, com pessoal qualificado, com políticas de acesso, com acompanhamento e avaliações compatíveis, entre outros, e desenvolva atividades educativas por estudantes e profissionais da educação que estejam em lugares e tempos diversos (Brasil, 2017).

Para António Moreira e Schlemmer (2020) elucida que a modalidade de ensino remoto emergencial, ou aula que pressupõe o distanciamento geográfico de professores e estudantes e vem sendo adotada nos diferentes níveis de ensino, por instituições educacionais no mundo todo, em função das restrições impostas pelo COVID-19, que impossibilita a presença física de estudantes e professores nos espaços geográficos das instituições educacionais.

\subsection{Os desafios da aprendizagem online}

Prensky (2001) elucida que os professores têm que atuar como permanentes aprendizes e aprender a se comunicar na linguagem e estilo de seus estudantes.

Dias (2016) ressalta que o digital produziu uma mudança na discursividade do mundo nas relações históricas, sociais e ideológicas, na constituição dos sujeitos e dos sentidos, mas também na forma dos relacionamentos, do trabalho, da mobilidade, dos encontros, até mesmo do fazer científico, do qual faz parte a maneira de sua produção e seus meios de circulação.

Coscarelli (2018) comenta que "aprendizes autônomos, críticos, bem-informados, cooperativos, colaborativos e que saibam usufruir plenamente, com segurança e com responsabilidade, das oportunidades que lhes são oferecidas nos ambientes digitais".

Para Brasil (2018) o potencial da escola como espaço formador e orientador para a cidadania consciente, crítica e participativa.

Tal fato pode estar associado ao escasso repertório dos professores em relação às ferramentas digitais disponíveis, uma vez que a maioria dos professores utiliza recursos mais básicos, como Pacote Office, Youtube e Redes Sociais (Lagarto, 2013).

\subsection{O aprendizado online e sua eficácia}

Nóvoa (2001) entende que, mais importante do que formar, é formar-se e que o aprender contínuo é essencial à profissão docente, sendo marcado pela própria pessoa do professor, como agente, entendendo a instituição escolar, como um espaço de crescimento profissional permanente. A bagagem essencial de um professor adquire-se na escola, através da experiência e da reflexão sobre a experiência. O que dá sentido à formação é o diálogo entre os professores, a análise rigorosa das práticas e a procura coletiva das melhores formas de agir” (Ibidem, 2011). 
Freire (2011) expõem que em um contexto educacional marcado por uma cultura movente, que exige a compreensão de que ninguém se forma realmente, se não assume a responsabilidade no ato de formar-se.

Brasil (2013) ressalta que é necessário repensar a formação dos professores para que possam enfrentar as novas e diversificadas tarefas que lhes são confiadas na sala de aula e além dela

De forma crítica e problematizadora, com vistas a possibilitar aos alunos a construção de competências e habilidades que os auxiliem a interagir e interpretar as múltiplas linguagens que compõem os diferentes gêneros textuais e discursivos (Rojo, 2012).

Canclini (2015) pondera que o acesso desses alunos, às atividades, o retorno não foi como a gente queria, né? Nesse caso, a dificuldade de acesso à internet interferiu diretamente no alcance dos objetivos de ensino da professora. Esse depoimento nos lembra de que os artefatos tecnológicos não são instrumentos acessíveis a toda população, evidenciando o chamado tecno-apartheid.

Para esta professora os problemas enfrentados pelos estudantes estão relacionados à falta de acesso à internet e à falta de dispositivos como tabletes, notebooks e computadores que os permitam acompanhar, de modo satisfatório, as discussões e atividades propostas no ambiente digital. Sabemos que o celular permite a portabilidade, interatividade social e individualidade (Alves et al., 2019).

"Isso implica uma mudança de mentalidade formativa diante da desafiadora realidade em que nos encontramos" (Campos, 2007).

De acordo com Alves e outros autores (2019) "o ambiente escolar ainda não dialoga com o mundo permeado pelas tecnologias digitais e seus dispositivos móveis".

"Em que os alunos vão lidar com diferentes recursos para trabalhar com imagens, filmes, áudios, nas quais eles serão encorajados a fazer suas próprias produções, aprimorando o letramento digital e promovendo a autoria e a cidadania" (Coscarelli, 2019).

Para Moran (2017) “A combinação dos ambientes mais formais com os informais (redes sociais, wikis, blogs), feita de forma inteligente e integrada, nos permite conciliar a necessária organização dos processos com a flexibilidade de poder adaptá-los à cada aluno e grupo".

\subsection{A importância da disseminação do conhecimento é destacada por meio do Covid-19}

"Não garante que ele fará uso pedagógico dos seus conhecimentos com seus alunos" (Perrenoud, 2000), salienta sobre os professores.

Segundo (Tori, 2017) e "em uma atividade virtual é muito mais difícil prender a atenção do aprendiz e garantir seu envolvimento e participação, mesmo em cursos bem planejados".

Alexander et al. (2020) indica "no meio dessa pandemia, os professores estão ensinando, os pais estão ensinando e apoiando o aprendizado, e muitas crianças são responsáveis por seu próprio aprendizado".

\subsection{Impactos do Covid-19 na pesquisa em andamento}

A educação deveria pautar-se sempre na busca pela transformação e preparação para o futuro, considerando os processos sociais e culturais articulados a esse fenômeno. O que é possível identificar, no entanto, são sinais históricos desordenados entre o que a escola regular oferece e o que a sociedade efetivamente necessita. A impressão é que a educação escolar anuncia vislumbrar o futuro, mas o observa com óculos do passado - analogia próxima a de Lemos (2018)

De modo semelhante, Kenski (2020) e Santana (2019) informam a educação na contemporaneidade ainda permanece com o desafio de educar estudantes do século XXI, com professores do século XX e escolas do século XIX. 
Sales (2013) discorre que circunstancialmente diante dessas revoluções, ao idealizar a educação para o século XXI, a evocação por um processo democrático e inclusivo é unanimidade. Isso implica defender e projetar processos educativos não apenas coerentes com o contexto sociocultural, mas humanizados e harmonizados com a potencialidade integrada de tecnologias diferentes de outros recursos tecnológicos desenvolvidos pela humanidade anteriormente, permitindo incluir e integrar.

Santana (2020) enfatiza que, embora o distanciamento e o isolamento, na maioria dos casos, sejam físicos e não sociais.

Brasil (2017) indica que contemplada especialmente no artigo 80 da LDB, a EaD tem hoje um Decreto n ${ }^{\circ}$ 9.057/2017, que a define em seu art. $1^{\circ}$ como: modalidade educacional na qual a mediação didático-pedagógica nos processos de ensino e aprendizagem ocorra com a utilização de meios e tecnologias de informação e comunicação, com pessoal qualificado, com políticas de acesso, com acompanhamento e avaliação compatíveis, entre outros, e desenvolva atividades educativas por estudantes e profissionais da educação que estejam em lugares e tempos diversos.

Sales e Pinheiro (2018), defendendo o que chamam convergência entre as modalidades presencial e a distância, enquanto uma decorrência natural da inserção das TIC nos processos formativos destacam como aspecto necessário à implementação de práticas híbridas, o desenvolvimento de uma cultura institucional que agregue naturalmente processos formativos com presencialidade física ou com mediação tecnológica, como processos diversos, mas igualmente promotores do desenvolvimento das habilidades, conteúdos e produções que se almeja.

De acordo com esta regulamentação as IES podem ofertar entre $20 \%$ e $40 \%$ da carga horária total dos seus cursos na modalidade à distância, considerando as condições e exigências ali especificadas: [...] incluir métodos e práticas de ensinoaprendizagem que incorporem o uso integrado de tecnologias de informação e comunicação - TIC para a realização dos objetivos pedagógicos, material didático específico, bem como a mediação de tutores e profissionais da educação com formação na área do curso e qualificados em nível compatíveis ao previsto no projeto pedagógico do curso - PPC e no plano de ensino da disciplina, que deverão descrever as atividades realizadas a distância, juntamente com a carga horária definida para cada uma, explicitando a forma de integralização da carga horária destinada às atividades on-line. (BRASIL, 2017, p 2.).

Santos (2019) diz que a educação on-line é compreendida como um complexo de ações de ensino-aprendizagem mediadas por tecnologias digitais que fortalecem práticas interativas e hipertextuais.

A Educação On-line é uma perspectiva pedagógica que pode ser assumida como potencializadora de situações de aprendizagem mediadas por encontros presenciais, à distância ou em processos híbridos. (Ibidem, 2019)

Santos (2019) sustenta é a de que, muitas vezes, o paradigma educacional dos processos de ensino com mediação tecnológica digital são centrados em pressupostos pedagógicos pautados na transmissão, adotando lógicas massivas das mídias de massa e autoaprendizagem reativa, ao tempo que nas vivências do ciberespaço, no contexto da cibercultura, os sujeitos interagem com as interfaces para produzir e compartilhar coletivamente e em rede, informações e conhecimento. A educação on-line, nesse sentido, tem princípios e fundamentos engendrados a partir de elementos centrais da cibercultura: o social, a rede e a autoria.

Santo e Trindade (2020) demarcam o surgimento do ensino remoto emergencial (ERE) a partir de situações atípicas como pandemias e outras catástrofes e o define como possibilidade para a continuidade das atividades pedagógicas com o objetivo de diminuir os prejuízos derivados da suspensão das aulas presenciais.

\subsection{Impactos na educação: escolas}

As TDIC podem ser ressignificadas e ocupar um espaço importante no processo de ensino-aprendizagem, em todos os níveis de ensino (Avelino e Mendes, 2020, Barreto e Rocha, 2020, Martins, 2020). 
Para Hodges (2020), o planejamento pedagógico em situações atípicas exige resolução criativa dos problemas, demandando transposição de ideias tradicionais e proposição de estratégias pedagógicas diferenciadas para atender à demanda dos estudantes e professores. Além disso, os referidos pesquisadores destacam que tais soluções podem ser duradouras, favorecendo, dessa forma, a resolução de problemas e paradigmas que até então pareciam insuperáveis.

Conforme Martins (2020), o cenário da pandemia trouxe novas e velhas reflexões e preocupações para o campo educacional, tais como "[...] as condições de trabalho do docente, a qualidade do processo de ensino-aprendizagem, a relevância e o significado dos temas a serem abordados, o desenvolvimento de práticas pedagógicas centradas no estudante $[\ldots] "$.

Segundo Coll e Monereo (2010), apenas incorporar os recursos tecnológicos não transforma os processos educacionais, no entanto, "[...] modifica substancialmente o contexto no qual estes processos ocorrem e as relações entre seus atores e as tarefas e conteúdo de aprendizagem, abrindo, assim, o caminho para uma eventual transformação profunda desses processos".

França Filho, Antunes e Couto (2020), os quais indicam a relevância de se considerar a técnica e a natureza funcional das TDIC.

Segundo Avelino e Mendes (2020), “[...] além de todas as dificuldades já existentes, os alunos terão de enfrentar um sistema de educação que não tem estrutura suficiente para ampará-los frente a essa nova realidade".

Destarte, em uma sociedade cada vez mais envolvida com a tecnologia, é interessante notar o crescente número de professores que têm aliado ferramentas tecnológicas à sua prática pedagógica, associando, portanto, o contexto da cibercultura (Levy, 1999) à sua didática em sala de aula, com a finalidade de ensinar a geração nascida na era digital (Palfrey e Gasser, 2011).

Avelino e Mendes (2020) argumentam que, no momento anterior ao isolamento social, existia a dificuldade de os recursos tecnológicos chegarem até as escolas; neste contexto pandêmico, os estudantes têm enfrentado o desafio de não possuírem recursos suficientes para acompanhar as aulas virtuais e realizar as atividades de modo on-line.

\subsection{Impactos na educação: famílias}

Andersen e Nielsen (2019) analisam as consequências de uma grande falha de TI no sistema de teste na Dinamarca. Como resultados disso, algumas crianças não puderam fazer o teste. Os autores descobriram que a participação no teste aumentou a pontuação em um teste de leitura dois anos depois em $9 \%$ de um desvio padrão, com efeitos semelhantes em matemática. Esses efeitos são maiores para crianças de ambientes desfavorecidos.

É importante ressaltar que o bloqueio de instituições não afetam apenas as avaliações internas. Outra solução é substituir os exames cegos por avaliações do professor. As evidências de várias configurações mostram desvios sistemáticos entre exames não cegos e cegos, onde a direção do preconceito normalmente depende se a criança pertence a um grupo que geralmente tem um bom desempenho (Burgess e Greaves, 2013, Rangvid, 2015).

Maurin e McNally (2008) mostram que o abandono dos procedimentos normais de exame na França em 1968 (após os distúrbios estudantis) levou a consequências positivas no mercado de trabalho de longo prazo para a coorte afetada.

A pesquisa mostra que os empregadores usam credenciais educacionais, como classificações de graduação e médias de notas para classificar os candidatos (Piopiunik et al. 2020). O aumento do ruído dos sinais dos candidatos irá, portanto, potencialmente reduzir a eficiência de correspondência para os recém-formados no mercado de trabalho, que podem experimentar um crescimento mais lento dos rendimentos e taxas de separação de empregos mais altas. Isso é caro para o indivíduo e também para a sociedade como um todo (Fredriksson et al. 2018). 


\subsection{Ciência aberta é fundamental para a luta contra covid-19}

Segundo o site Wellcome Trust (2021), apela aos pesquisadores, periódicos e financiadores para garantir que os resultados da pesquisa e os dados relevantes para este surto sejam compartilhados de forma rápida e abertos para informar a resposta da saúde pública e ajudar a salvar vidas.

"Esta é uma experiência muito diferente de qualquer surto do qual eu tenha participado", disse o epidemiologista Marc Lipsitch (2008), da Escola de Saúde Pública Harvard TH Chan. A intensa comunicação catalisou um nível incomum de colaboração entre os cientistas que, combinado com os avanços científicos, permitiu que a pesquisa avançasse mais rápido do que durante qualquer surto anterior. "Uma quantidade de conhecimento sem precedentes foi gerada em 6 semanas", disse Jeremy Farrar, chefe do Wellcome Trust.

\subsection{Ciência aberta responsável}

Para Nóvoa (2020), os sistemas de educação não sabem como lidar com essa crise especificamente e é preciso, reconhecer o não saber, entendendo, porém, que é essencial agir em defesa de uma educação que seja, sobretudo, pautada na luta contra as desigualdades sociais. Assim, interromper as atividades pedagógicas não deveria ser uma opção sob o risco de o estudante não retornar ao espaço escolar.

Tomazinho (2020) comenta obviamente que se deve considerar que a escola convencional nunca deve ter pensado na possibilidade de seus alunos e professores não poder frequentar as salas de aula.

Pretto, Bonilla e Sena (2020) relatam que o Ensino remoto, deste modo, indica uma sequência reducionista: da educação ao ensino; do ensino à mera realização de atividades remotas que dispensam o efetivo trabalho docente de mediação, diálogo, interação; da relação da escola com demais mediações sociais que ela possibilita.

Pretto, Bonilla e Sena (2020) destacam que os docentes, em regra geral, acessam e se apropriam com facilidade das redes sociais digitais, mas não conseguem articular esse uso com o cotidiano escolar, pois são lógicas diferentes que não dialogam.

\subsection{A geração $Z$ está tendo uma experiência educacional diferente de qualquer outra geração}

FagundeS (2011), Facco et al. (2015) indicam que os nascidos a partir de 1993 compõem esta geração, também chamados de Zs, Zees ou Zeds.

Já Bastos e De Andrade Biar (2015) comentam que a geração de dados deu-se por meio de entrevistas semiestruturadas elaboradas com o intuito de encorajar a emergência de narrativas.

Vivemos na era do digital. Do reflexo das telas na face de nossos filhos, diariamente imersos no mar infinito da web. Da conexão constante: em casa pelo modem, nas ruas por meio dos celulares e em cafés com redes sem fio (wireless). Nos últimos anos, esse domínio da internet chegou a um dos locais mais protegidos pela sociedade: a escola (Shinyashiki, 2020)

A metade mais jovem, disse Thornburgh (2010), está passando por uma transição mais suave porque é ainda mais nativa da tecnologia usada em uma sala de aula remota. É menos perturbador para eles no curto prazo, mas mais induzindo mudanças no longo prazo - as expectativas da Geração Z para essas ferramentas persistirão no futuro.

Como deveríamos chamar estes "novos" alunos de hoje? Alguns se referem a eles como N-gen [Net] ou D-gen [Digital]. Porém a denominação mais utilizada que eu encontrei para eles é Nativos Digitais. Nossos estudantes de hoje são todos "falantes nativos" da linguagem digital dos computadores, vídeo games e internet (Prensky 2020).

Segundo Thornburgh (2010), disse que antecipa efeitos positivos prolongados na educação para a Geração Z, a primeira geração digitalmente nativa, agora espera ainda mais conectividade virtual com amigos e materiais de aprendizagem. A maior parte da socialização acontece na escola e os alunos estão tentando preencher esse vazio. A pandemia ampliou 
parcialmente uma já forte demanda e desejo de se conectar com colegas, o que Thornburgh (2010), disse acreditar que levará a mais orientação e tutoria entre pares no futuro, e que antecipa o conceito de uma "sala de aula invertida", na qual os alunos navegam sozinhos pelo conteúdo de aprendizagem - primeiro consumindo o conteúdo por conta própria e, em seguida, fazendo perguntas. Seria um passo em direção a um aprendizado mais independente em sala de aula, permitindo que os alunos aprendam no ritmo que for melhor para eles.

Cherubin (1990), alerta que atualmente ocupando as classes de ensino fundamental e médio, a "geração Z" acabou com o reinado das aulas expositivas. Já não bastam intercalares conteúdos e exercícios: para atrair a atenção dos jovens, a tecnologia é a principal aliada dos professores.

Thornburgh (2010), espera uma demanda maior por oportunidades de aprendizado adaptativo e um aumento nos recursos adaptativos daqui para frente. Por exemplo, disse ele, um aluno da nona série que se move autonomamente em um ritmo mais rápido pode conseguir entrar na matemática da $11^{\mathrm{a}}$ série no futuro.

Mc Crindle (2011) afirma que essa geração é artística e adaptativa, pois tem muita intimidade com a mídia e as artes.

Para Thornburgh (2010), espera que isso acelere mais fortemente a implementação de estruturas mais motivacionais e criativas para os alunos. Esses são aspectos positivos tanto para a Geração Z quanto para seus pais. "Pessoas que antes hesitavam sobre eles foram forçados a implementá-los e ver se são eficazes".

$\mathrm{Na}$ área da educação, por exemplo, já se percebe de forma mais clara as mudanças de uma geração para outra; as crianças chegam com maior conhecimento adquirido quando comparado às gerações anteriores (Facco et al., 2015)

Segundo Thornburgh (2010), servindo como um campo de jogo igual para crianças de diferentes meios para convergir. "Durante o dia escolar, é quando crianças de diferentes meios tendem a convergir", disse ele. "Eles têm a mesma experiência, apesar do histórico socioeconômico, mas esse tempo acabou. Grande parte do semestre da primavera se tornou como as férias de verão - quando crianças com pouco acesso a recursos perdem muito terreno para os colegas."

Bennett et al. (2008) afirmam que, a presença da tecnologia nas salas de aula é nítida, e que os alunos ficam frustrados quando esta não funciona adequadamente ou é inexistente, porém alertam que os jovens devem ser orientados, de como reconhecer a fidelidade e qualidade das informações.

Thornburgh (2010) ressalta que o abismo também está surgindo de uma divisão digital - há uma ligação entre o status socioeconômico e a conectividade com a Internet.

\subsection{Educação escolar em casa}

Os alunos correm o risco de perda de aprendizagem. Mas, independentemente da origem, acrescentou Thornburgh (2010), todos os alunos correm o risco de ficar para trás academicamente. E revela que: "Muito do nosso currículo tende a ser baseado no que vem antes".

Enquanto os estados e distritos locais estão colocando as decisões nas mãos dos pais para continuar a educação de seus filhos, Thornburgh (2010), os pais não têm dados sobre essa decisão. Essa perda de aprendizado pode ter efeitos de longo prazo quando se trata de entrar na faculdade, ampliando a batalha já cansada pelo acesso à igualdade de oportunidades.

Segundo Thornburgh (2010), sabemos que o acesso e a conclusão das credenciais da faculdade são a melhor e mais segura maneira de sair da pobreza. As crianças que não estão na fronteira terão dificuldade em recuperar o atraso.

Há de se valorizar todo o tipo de iniciativa que se tem realizado, por professores ou gestores educacionais, já que "a inovação e criatividade das redes, escolas, professores e estudantes podem apresentar soluções mais adequadas" (Brasil, 2020).

\subsection{Bloqueio da Covid-19: impacto da pandemia global no setor de educação}

A Human Rights Watch (2020), informou que mais de 1,5 bilhão de alunos já estão fora da escola. A perda 
generalizada de empregos e renda, juntamente com a insegurança econômica entre as famílias, provavelmente também aumentarão o trabalho infantil, a exploração sexual, a gravidez na adolescência, entre outros males.

Cabe destacar que a incorporação das TDIC nas instituições escolares ainda é um entrave na realidade nacional; problemas de infraestrutura e de formação docente deficitária são variáveis importantes que interferem diretamente em uma utilização crítica, intencional e produtiva das tecnologias (Braga, 2018, Thadei, 2018).

"equipar os professores com as competências necessárias para que eles possam explorar plenamente o potencial das tecnologias digitais" (Tarouco, 2019, p. 33).

Conselho Nacional de Educação (CNE) enfatiza a necessidade de levar "em consideração o atendimento dos objetivos de aprendizagem e o desenvolvimento das competências e habilidades a serem alcançadas pelos estudantes em circunstâncias excepcionais provocadas pela pandemia" (Brasil, 2020, p. 23).

\subsection{Desigualdade entre crianças trazida à tona}

Cruz, Borges e Nogueira Filho (2020) citam que de antemão, é preciso compreender que ensino remoto não é sinônimo de aula on-line. Há diferentes maneiras de estimular a aprendizagem à distância e, se bem estruturadas, atividades educacionais podem cumprir mais do que uma função puramente acadêmica.

Viner et al (2020) questionam que outros surtos anteriores de coronavírus, como SARS e MERS, também fornecem informações limitadas sobre a eficácia do fechamento de escolas e nenhum dado sobre custo-efetividade.

Desta forma, Franco (2020) destaca que cada docente está buscando alternativas para dar conta das suas atividades pedagógicas nessa realidade atual, adaptando-se à situação, buscando desenvolver novas metodologias, com uso de recursos educacionais digitais.

O Envolvimento das famílias também é chave, já que poderão ser importantes aliados no momento e no pós-crise (Todos pela Educação, 2020).

Salvador (1999) comenta que a base da proposta é um processo educativo guiado pela satisfação em aprender o conteúdo de forma ativa, desenvolvendo as funções morais e intelectuais do indivíduo, descaracterizando o processo de educação de cunho estritamente memorístico.

Para Mori e Cunha (2020), a ABP fundamenta-se em princípios educacionais construtivistas e em resultados de pesquisas em ciência cognitiva.

Esses princípios mostram que a aprendizagem não é um processo de recepção passiva e acúmulo de informações, mas um processo de construção de conhecimento (Ribeiro, 2008).

\subsection{Falta de prontidão e infraestrutura para professores}

Segundo a Unesco (2020), uma dessas indica a necessidade de "analisar a resposta e escolher as melhores ferramentas", ou seja, considerar o contexto da comunidade escolar e, dessa maneira, encontrar as possibilidades reais, mesmo que não sejam as ideais. Assim, ao propor o ERE surge a necessidade da reorganização das unidades.

Nem todos os professores possuem formação para o uso da TDIC e "o fato de o professor ser usuário de tecnologia não lhe garante a transposição didática” (Modelski, Giraffa e Casartelli, 2019).

Barreto e Rocha (2020) destacam o quanto os professores se reinventam no período de pandemia: mesmo sem uma preparação adequada, há uma busca incansável por oferecer o melhor aos seus estudantes, fato observado, por exemplo, no DSC dos professores da escola privada, no qual consta a menção a um "[...] processo de produção das aulas com mais qualidade".

De forma repentina, os professores tiveram suas atividades de trabalho profundamente alteradas, pois, além de 
reorganizar as atividades letivas, tanto da Educação Básica (EB) quanto da Educação Superior (ES), é preciso "considerar propostas que não aumentem a desigualdade ao mesmo tempo em que utilizem a oportunidade trazida por novas TDIC para criar formas de diminuição das desigualdades de aprendizado" (Brasil, 2020, p. 3).

Conforme Couto, Couto e Cruz (2020) deve-se considerar os recursos disponíveis, aos docentes e alunos, tanto em termos de tecnológicos quanto humanos, como a necessidade de um adulto para auxiliar a criança, no que se refere às habilidades necessárias ao manuseio dos dispositivos, entre outros.

\section{Procedimentos Metodológicos}

Os procedimentos metodológicos estão embasados no levantamento de informações através de pesquisas bibliográficas em publicações online como revistas, jornais, legislação e a busca de dados em relatórios virtuais de instituições renomadas na área da saúde e educação.

A pesquisa bibliográfica é aquela que se realiza, segundo Severino (2007), a partir do: [...] registro disponível, decorrente de pesquisas anteriores, em documentos impressos, como livros, artigos, teses etc. Utilizam-se dados de categorias teóricas já trabalhadas por outros pesquisadores e devidamente registrados. Os textos tornam-se fontes dos temas a serem pesquisados. O pesquisador trabalha a partir de contribuições dos autores dos estudos analíticos constantes dos textos (Severino, 2007, p.122).

Segundo Marconi e Lakatos (1992), a pesquisa bibliográfica é o levantamento de toda a bibliografia já publicada, em forma de livros, revistas, publicações avulsas e imprensa escrita. A sua finalidade é fazer com que o pesquisador entre em contato direto com todo o material escrito sobre um determinado assunto, auxiliando o cientista na análise de suas pesquisas ou na manipulação de suas informações. Ela pode ser considerada como o primeiro passo de toda a pesquisa científica

Gil (2008) a pesquisa é o procedimento racional e sistemático que tem por objetivo proporcionar respostas aos problemas propostos pelo pesquisador. Sendo assim, a pesquisa é requerida quando não há informações suficientes ou quando esta informação se encontra em desordem, por isso este procedimento visa atender adequadamente este aspecto do problema pesquisa elencado.

A pesquisa também deve ser desenvolvida mediante a utilização dos conhecimentos disponíveis e cuidadosa aplicação da metodologia de pesquisa, técnicas e procedimentos científicos. Esta se desenvolve com inúmeras fases, isso quer dizer, desde a formulação do problema até a apresentação dos resultados. (GIL, 2008).

Diante do exposto, define-se esta pesquisa como exploratória de caráter qualitativo, uma vez que visa identificar e esclarecer a influência direta permitindo assim maior aproximação com o cotidiano e as experiências vividas pelos próprios sujeitos (Gil, 2011).

As pesquisas científicas podem ser classificadas quanto à natureza (básica ou aplicada), quanto ao tipo (bibliográfica, documental, campo, experimental, exploratória, descritiva, entre outras) e quanto à abordagem (quantitativa ou qualitativa) (André, 1984; Thiollent, 1985, Ludke; André, 1986; Gil, 1991, Santos, 1989, Rodrigues, Limena, 2006; Severino, 2007, Yin, 2010, Appolinário, 2011).

Na perspectiva de Appolinário (2011), a pesquisa ou estudo exploratório tem por objetivo "aumentar a compreensão de um fenômeno ainda pouco conhecido, ou de um problema de pesquisa ainda não perfeitamente delineado". Podemos dizer que essa modalidade de pesquisa é prospectiva. Acrescido a isso, essa modalidade pode parecer uma pesquisa bibliográfica ou documental quando o foco da investigação está centrado em documentos, ou ainda, quando o pesquisador realiza um levantamento teórico acerca de um tema que pretende estudar e investigar. 
Segundo o ponto de vista de Severino (2007), a pesquisa exploratória busca apenas levantar informações sobre um determinado objeto, delimitando assim um campo de trabalho, mapeando as condições de manifestação desse objeto. $\mathrm{Na}$ verdade, ela é uma preparação para a pesquisa explicativa.

\section{Análise dos Dados}

Nesse capítulo serão apresentados os dados referentes à pesquisa.

Os resultados desta pesquisa corroboram a literatura quando apontam as fragilidades do ensino remoto, como demonstram Alonso e Silva (2018). Para os autores, há fatores limitantes como a falta de acesso à internet, a instabilidade do sinal Wi-Fi, a ausência de recursos tecnológicos (smartphone, notebook, tablet entre outros), qualidade da transmissão da aula, a facilidade para a distração do aluno e a ergonomia, relacionada ao ambiente de estudo. Os autores afirmam também que estes são fatores que possuem relação com o processo de aprendizagem do acadêmico, isto é, à medida que as situações complicadoras aumentam, a satisfação dos alunos diminui, reduzindo assim a participação desses discentes nas discussões durante a aula remota.

O Instituto Brasileiro de Geografia e Estatística (IBGE), descreveu que em 2018, 1 a cada 4 pessoas não possuíam acesso à internet, o que corresponde a aproximadamente 46 milhões de indivíduos em todo o país.

Kenski (2015), afirma que é válido considerar que muitos estudantes possuem dificuldades no acesso às plataformas utilizadas pelas instituições de ensino, principalmente por não possuírem ou possuírem redes fracas de internet em suas residências.

Com isso, a introdução de metodologias ativas é extremamente importante para modificar as concepções negativas frente ao modelo de educação on-line, bem como adaptar as formas pela busca do conhecimento (Rodrigues e Lemos, 2019).

Trabalhando ao lado de professores, os sistemas de aprendizagem digitais inteligentes não apenas ensinam ciências aos alunos, mas podem, simultaneamente, observar como eles estudam o tipo de tarefas e pensamentos que os interessam e os tipos de problemas que consideram enfadonhos ou difíceis.

Os sistemas podem então adaptar a experiência de aprendizagem para se adequar aos estilos de aprendizagem pessoais dos alunos com grande granularidade e precisão. Da mesma forma, os laboratórios virtuais podem dar aos alunos a oportunidade de projetar, conduzir e aprender com os experimentos, em vez de apenas aprender sobre eles.

Além disso, a tecnologia não muda apenas os métodos de ensino e aprendizagem, mas também pode elevar o papel dos professores de transmitir o fundamento recebido para trabalhar como multiplicadores de conhecimento, como treinadores, mentores e avaliadores.

À medida que o mundo se torna cada vez mais interconectado, também aumentam os riscos que enfrentamos. A pandemia COVID-19 não parou nas fronteiras nacionais. Afetou pessoas independentemente de nacionalidade, nível de escolaridade, renda ou gênero. Mas o mesmo não aconteceu com suas consequências, que atingiram com mais força os mais vulneráveis. Esta crise expôs as muitas inadequações e injustiças em nossos sistemas de educação - desde o acesso à banda larga e computadores necessários para a educação online e os ambientes de apoio necessários para focar na aprendizagem, até o desalinhamento entre recursos e necessidades.

A pandemia COVID-19 também teve um impacto severo no ensino superior, pois as universidades fecharam suas instalações e os países fecharam suas fronteiras em resposta ao bloqueio medidas. Embora as instituições de ensino superior tenham rapidamente substituído as aulas presenciais pelo aprendizado online, esses encerramentos afetaram o aprendizado e os exames, bem como a segurança e o status legal dos alunos internacionais em seus país anfitrião.

Talvez o mais importante, a crise levanta questões sobre o valor oferecido por uma educação universitária que inclui networking e oportunidades sociais, bem como conteúdo educacional. Para permanecerem relevantes, as universidades 
precisarão reinventar seus ambientes de aprendizagem para que a digitalização expanda e complemente as relações alunoprofessor e outras.

No entanto, os desafios não terminam com a crise imediata. Em particular, os gastos com educação podem ficar comprometidos nos próximos anos. Como os fundos públicos são direcionados para a saúde e o bem-estar social, os gastos públicos de longo prazo com a educação estão em risco, apesar dos pacotes de estímulo de curto prazo em alguns países. O financiamento privado também se tornará escasso à medida que a economia enfraquece e o desemprego aumenta.

No nível superior, o declínio na mobilidade de estudantes internacionais devido às restrições de viagens já está reduzindo os fundos disponíveis em países onde os estudantes estrangeiros pagam taxas mais altas. De forma mais ampla, o bloqueio exacerbou a desigualdade entre os trabalhadores.

Embora o home office e as aula on line seja frequentemente uma opção para os mais qualificados, raramente é possível para aqueles com níveis de educação mais baixos, muitos dos quais estiveram na linha de frente na resposta à pandemia, prestando serviços essenciais à sociedade. A pandemia de COVID-19 mergulhou o mundo numa recessão, o desempenho em 2020 será pior do que durante a crise financeira global, os danos econômicos não param de crescer em todos os países, acompanhando o forte aumento do número de casos (Gráfico 1) e de medidas de contenção impostas pelos governos.

Gráfico 1: Casos confirmados de Covid 19 (2020).

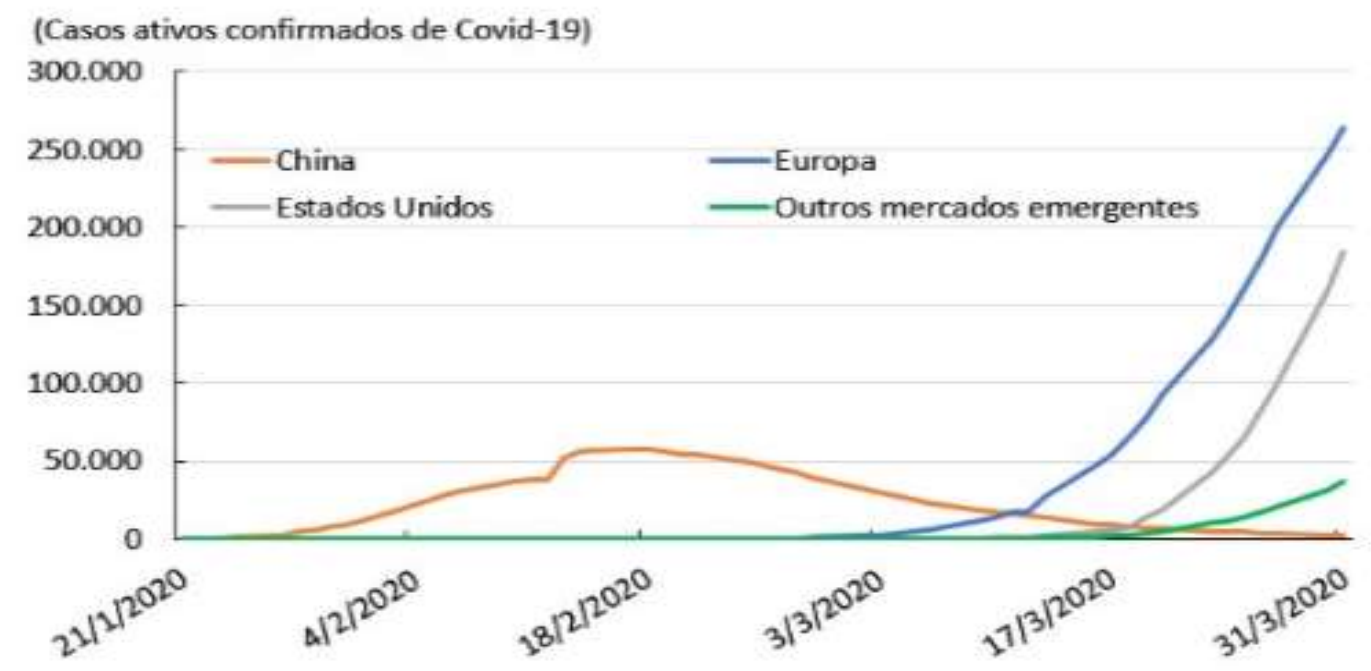

Fonte: Johns Hopkins University (2020).

Sobre as questões que o Gráfico 1 mostra, a propagação do vírus foi muito rápida, com os primeiros casos registrados na China, e se alastrando para outros países. Em 31 de dezembro de 2019, a China notificou a OMS (2019), de vários casos de pneumonia de origem desconhecida em Wuhan, província de Hubei. Uma semana mais tarde, em 7 de janeiro, foi determinado que estes casos eram causados por um novo coronavírus. O vírus propagou-se muito rapidamente, primeiro no interior de Wuhan e da província de Hubei, depois para o resto da China.

Ao final de janeiro, a China tinha quase 10.000 casos confirmados de COVID-19, a doença causada pelo coronavírus. Passados apenas um mês, no final de fevereiro, havia quase 80.000 casos registrados no país (Gráfico 1).

Na continuidade da discussão, pode-se dizer que em relação ao Gráfico 1 o primeiro caso foi confirmado na Tailândia em 13 de janeiro, tendo sido comunicados outros casos pouco depois na Coreia e em Taiwan. Nas Américas, o coronavírus chegou aos Estados Unidos em 15 de janeiro de 2020, quando um homem que tinha visitado Wuhan voltou para casa no estado de Washington e seu teste deu positivo no dia 20 de janeiro. Na Europa, o coronavírus chegou por meio da França, tendo os dois primeiros casos sido confirmados em 22 de janeiro. A Itália, o país mais afetado em termos de perda de vidas, comunicou 
o seu primeiro caso em 31 de janeiro. Desde então, o vírus se alastrou como um incêndio onde o número de casos ativos cresceu rapidamente, segundo Johns Hopkins University (2020).

Percebeu-se, nesta pesquisa aqui demonstrada, que os professores relataram grande necessidade de treinamento no uso de tecnologias de informação e comunicação (TIC): Durante a pandemia, o aprendizado remoto tornou-se uma tábua de salvação para a educação, mas as oportunidades que as tecnologias digitais oferecem vão muito além de uma solução temporária durante uma crise.

A tecnologia digital oferece respostas inteiramente novas para a questão do que as pessoas aprendem como aprendem e onde e quando aprendem. A tecnologia pode permitir que professores e alunos acessassem materiais especializados muito além dos livros didáticos, em vários formatos e de maneira que podem fazer a ponte entre o tempo e o espaço.

O impacto da pandemia na educação, traz à tona a discussão sobre a urgência de mecanismos para a implementação da educação à distância em nosso país. Sabe-se que a tecnologia é um fator primordial no que diz respeito à evolução digital, permitindo experiências proveitosas especificamente no âmbito educacional.

Assim, professores e alunos tiveram que se adaptar às aulas a distância e utilizar toda a criatividade para dar continuidade às atividades escolares, utilizando para isso a Rede Mundial de Computadores (Internet) a qual foi um diferencial essencial neste processo juntamente com os diversos recursos tecnológicos disponíveis para a continuidade do processo de educação das pessoas.

\section{Considerações}

Este artigo objetivou abordar sobre como a tecnologia através da Internet, torna-se uma alternativa significativa e imprescindível para educação, durante o período da pandemia. Os procedimentos metodológicos estão embasados no levantamento de informações através de pesquisas bibliográficas em publicações online como revistas, jornais, legislação e a busca de dados em relatórios virtuais de instituições renomadas na área da saúde e educação.

Pode-se perceber, também, que artigo indica da importância que os países precisam pensar na não dependência de apenas um canal único de aprendizagem à distância para alcançar a todos. Além disso, expandir o acesso à Internet e outras soluções digitais para todos os alunos seria uma das principais prioridades de longo prazo para reduzir as vulnerabilidades de aprendizagem.

Mais de 1 bilhão de crianças correm o risco de ficar para trás devido ao fechamento de escolas com o objetivo de conter a disseminação da Covid-19. Para manter as crianças em todo o mundo aprendendo, os países têm implementado programas de educação à distância. Ainda assim, muitas das crianças no mundo - especialmente aquelas em famílias mais pobres - não têm acesso à Internet, computadores pessoais, TVs ou mesmo rádio em casa, ampliando os efeitos das desigualdades de aprendizagem existentes. Os alunos que não têm acesso às tecnologias necessárias para o aprendizado em casa têm meios limitados para continuar seus estudos. Como resultado, muitos correm o risco de nunca mais voltar à escola, desfazendo anos de progresso feito na educação em todo o mundo.

Segundo World Health Organization; (2020), com o fechamento de escolas em 188 países (em abril de 2020), há chance de parar essa epidemia, pois os casos assintomáticos parecem não alimentar de forma importante a transmissão, muitos deles estão explorando maneiras alternativas de fornecer educação contínua usando tecnologias como Internet, TV e rádio.

No entanto, o acesso a essas tecnologias é limitado em muitos países de baixa e média renda, especialmente entre as famílias pobres, as plataformas online foram os meios mais usados pelos governos para fornecer educação enquanto as escolas permaneceram fechadas.

Há de se pensar em metodologias para que os países não dependam de apenas um canal único de aprendizagem à distância para que possa, assim, alcançar a todos. Além disso, expandir o acesso à Internet e outras soluções digitais para todos 
os alunos seria uma das principais prioridades de longo prazo para reduzir as vulnerabilidades de aprendizagem.

É tão importante proteger professores, funcionários administrativos e alunos que estão em alto risco devido à idade ou condições médicas subjacentes, com planos para cobrir professores ausentes e continuar a educação remota para apoiar os alunos que não podem frequentar a escola. Os governos e as organizações de professores também podem precisar revisar as políticas de pessoal e frequência para acomodar as faltas relacionadas à saúde e apoiar o aprendizado remoto e híbrido, combinando o ensino online e presencial.

$\mathrm{O}$ investimento na capacidade humana será fundamental para isso. Os líderes escolares precisam ter a capacidade e o treinamento para estabelecer procedimentos para quando os alunos ou funcionários ficarem doentes e para colocar em prática o fechamento parcial ou total das escolas, quando necessário. Eles precisam ser capazes de conduzir uma avaliação de risco para professores e outros funcionários e tomar as medidas adequadas para apoiá-los.

Orientação e procedimentos eficazes são necessários para monitorar a saúde do aluno e da equipe, manter contato regular com as autoridades de saúde locais e atualizar os planos de emergência e listas de contato. Quando os alunos entram nas dependências da escola, pode ser necessário medir sua temperatura e isolar os alunos infectados e atendê-los por equipe médica especializada, sem estigmatizá-los.

Os professores também podem precisar ser testados antes da reabertura da escola e os gerentes de saúde e sanitários das escolas devem medir a temperatura dos professores quando eles entram nas instalações.

Da mesma forma, o pessoal administrativo e docente precisa de treinamento sobre como lidar com o vírus, reconhecer os riscos e implementar as medidas adequadas. Isso inclui a implementação de distanciamento físico e práticas de higiene, como aumentar a intensidade e a frequência das atividades de limpeza e desinfecção e melhorar as práticas de gerenciamento de resíduos. A equipe de limpeza precisa ser treinada em desinfecção e estar equipada com equipamentos de proteção individual, tanto quanto possível.

$\mathrm{O}$ artigo não tem a pretensão de estabelecer conceitos completos sobre o assunto, mas, sim, contribuir para a discussão de trabalhos futuros de como a tecnologia através da internet torna-se uma alternativa significativa e imprescindível para educação, durante o período da pandemia do COVID-19.

\section{Trabalhos Futuros}

Ao entrarmos na fase de recuperação do COVID-19, será fundamental refletir sobre o papel dos sistemas educacionais - e particularmente da educação profissionalizante - na promoção de sociedades resilientes. A crise global de saúde e o bloqueio que se seguiu trouxeram à tona profissões que muitas vezes eram tidas como certas, renovando nossa consciência de seu valor para a sociedade. Isso ajudou a restaurar um senso de estima por aqueles trabalhadores que trabalharam incansavelmente durante esse tempo para manter as economias à tona.

A mudança real geralmente ocorre em crises profundas, e neste momento existe a possibilidade de não retornarmos ao status quo quando as coisas voltarem ao "normal". Embora essa crise tenha implicações profundamente perturbadoras, inclusive para a educação, ela não tem resultados predeterminados. Será a natureza de nossas respostas coletivas e sistêmicas a essas rupturas que determinará como seremos afetados por elas.

Nesse sentido, a pandemia é também um apelo à renovação do compromisso com os Objetivos de Desenvolvimento Sustentável. Garantir que todos os jovens tenham a oportunidade de ter sucesso na escola e desenvolver conhecimentos, habilidades, atitudes e valores que lhes permitam contribuir para a sociedade está no centro da agenda global e da promessa da educação para nossa sociedade futura. A crise atual testou nossa capacidade de lidar com interrupções em grande escala. Cabe agora a nós construir como legado uma sociedade mais resiliente.

Como sugestões para trabalhos futuros entende-se que as tecnologias proporcionam que cidadãos construam seus 
saberes a partir de comunicação e interações com um mundo de pluralidades, no qual não há limites geográficos, culturais e a troca de conhecimentos e experiências é constante.

Dessa forma as tecnologias de informação e comunicação funcionam como molas propulsoras e recursos dinâmicos de educação, à medida que quando bem utilizadas pelos educadores e educandos permitem intensificar a melhoria das práticas pedagógicas desenvolvidas em sala de aula e fora dela.

\section{Referências}

Alexander, N., Gibbons, K., Marshall, S., Rodriguez, M. C., Sweitzer, J., \& Varma, K. (2020) Implementing Principles of Reimagine Minnesota in a Period of Remote Teaching and Learning. University of Minnesota: Minneapolis Foundation. https://conservancy. umn.edu/bitstream/handle/11299/212407/ReimagineCOVID19-Response.pdf?sequence $=1$

Andersen, S., Andersen, A., \& Nielsen-Kudsk, J. E. (2016) The Renin-Angiotensin-Aldosterone-System And Right Heart Failure In Congenital Heart Disease. International Journal Of Cardiology: Heart \& Vasculature, 11(2), 59-65.

André, M. E. D. A. de. (1984) Estudo de caso: seu potencial na educação. Cadernos de Pesquisa, São Paulo, 49, 51-54.

António Moreira, J., \& Schlemmer, E. (2020) Por um novo conceito e paradigma de educação digital online. Revista UFG, 20(26). https://www.revistas.ufg.br/ revistaufg/article/view/63438.

Appolinário, F. (2011) Dicionário de Metodologia Científica. (2a ed.), Editora Atlas.

Avelino, W. F., \& Mendes, J. G. (2020) A realidade da educação brasileira a partir da COVID-19. Boletim de Conjuntura, Boa Vista, 2(5), 56-62. https://revista.ufrr.br/boca/article/ view/AvelinoMendes/2892.

Barreto, A. C. F., \& Rocha, D. N. (2020) COVID 19 e Educação: Resistências, Desafios e (Im)Possibilidades. Revista ENCANTAR - Educação, Cultura e Sociedade. Bom Jesus da Lapa, 2,1-11. http://www.revistas.uneb.br/index.php/encantar/article/view/8480.

Bastos, L. C., \& De Andrade Biar, L. (2015) Análise de narrativa e práticas de entendimento da vida social. DELTA: Documentação e Estudos em Linguística Teórica e Aplicada, 31(4). https://www.scielo.br/pdf/delta/v31nspe/1678-460X-delta-31-spe-00097.pdf

Bennett, S. J., Maton, K. A. \& Kervin, L. K. (2008) The 'digital natives' debate: a critical review of the evidence. British Journal of Educational Technology, 39 (5), p. 775-786.

Braga, R. (2018) Apresentação. In: Fausto, C., Daros, T. A sala de aula inovadora: estratégias pedagógicas para fomentar o aprendizado ativo. Porto Alegre: Penso.

Brasil. (2013) Diretrizes Curriculares Nacionais da Educação Básica. MEC/SEB.

Brasil. (2018) Base Nacional Comum Curricular: educação é a base. MEC/SEB.

Brasil. (2017) Ministério da Educação. Decreto n ${ }^{\circ}$ 9.057, de 25 de maio de 2017. Regulamenta o art. 80 da Lei no 9.394 , de 20 de dezembro de 1996, que estabelece as diretrizes e bases da educação nacional. Diário Oficial da União, Brasília.

Brasil. (2020) Ministério da Educação. Conselho Nacional de Educação. Conselho Pleno. Parecer CNE/CP nº 5/2020.

Burgess, S. Y Greaves, E. (2013). Test Scores, Subjective Assessment, And Stereotyping Of Ethnic Minorities. Journal Of Labor Economics, 31(3), 535-576.

Campos, C. M. (2007) Saberes docentes e autonomia dos professores. Petrópolis, Vozes.

Canclini, N. G. (2015) Diferentes, desiguais e desconectados: mapas da interculturalidade. (3a. ed.), Editora UFRJ.

Cani, J. B., Sandrini, E. G. C., Soares, G. M., \& Scalzer, K. (2020) Educação e covid-19: a arte de reinventar a escola mediando a aprendizagem "prioritariamente" pelas TDIC. Revista IfesCiência, 6(1), 23-39. https://ojs.ifes.edu.br/index.php/ric/article/download/713/484

Cherubin, K. G. (1990) Para lidar com a geração Z, professores recorrem a redes sociais. http://mpcidadania.ning.com/profiles/blogs/para-lidar-comgeracao-z-professor-recorre-as-redes-sociais.

Coll, C., \& Monereo, C. (2010) Educação e Aprendizagem no século XXI: novas ferramentas, novos cenários, novas finalidades. In: Coll, C., monereo, C. (org.). Psicologia da educação virtual: aprender e ensinar com as tecnologias da informação e da comunicação. Porto Alegre: Artmed.

Coscarelli, C. V. (2019) Multiletramentos e empoderamento na educação. In: Ferraz, Obdália (org.). Educação, (multi)letramentos e tecnologias: tecendo redes de conhecimento sobre letramentos, cultura digital, ensino e aprendizagem na cibercultura. Salvador: Edufba.

Coscarelli, C. V. (2018) Perspectivas culturais de uso de tecnologias digitais e a educação. Revista Brasileira de Alfabetização, Belo Horizonte-MG, 1(8),3356. http://abalf.org.br/revistaeletronica/index.php/rabalf/article/view/293/211.

Couto, E. S., Couto, E. S., \& Cruz, I. M. P. (2020) \#Fiqueemcasa: Educação na Pandemia da Covid-19. Revista Interfaces Científicas Educação, Aracajú 8(3), 200-217. https://periodicos.set.edu. br/index.php/educacao/article/view/8777 
Cruz, P., Borges, J., \& Nogueira Filho, O. (2020) Nota técnica: ensino a distância na educação básica frente à pandemia da covid-19. Todos Pela Educação, [s. 1.]. https://www. todospelaeducacao.org.br/_uploads/_posts/425.pdf?1730332266=\&utm_source=conteudonota\&utm_medium=hiperlink-download.

Dias, C. A. (2016) análise do discurso digital: um campo de questões. Revista Eletrônica de Estudos do Discurso e do Corpo - REDISCO, Vitória da Conquista, 10(2), 8-20. http://periodicos.uesb.br/index.php/redisco/article/viewFile/6139/5880.

Facco, A. L. R., Obregon, S. L., Oliveira, L. R., Beltrame, G., \& Kruger, C. (2015) Compreendendo as aspirações de carreira de estudantes da geração z de escolas públicas. Anais do XX Seminário Interinstitucional de Ensino, Pesquisa e Extensão. UNICRUZ. Cruz Alta.

Fagundes, M. M. (2011) Competência Informacional e Geração Z: um estudo de caso de duas escolas de Porto Alegre. Trabalho de Conclusão de curso biblioteconomia, da Faculdade de Biblioteconomia e Comunicação da Universidade Federal do Rio Grande do Sul. Porto Alegre.

França Filho, A. L., Antunes, C. F., \& Couto, M. A. C. (2020) Alguns apontamentos para uma crítica da educação a distância (EaD) na educação brasileira em tempos de pandemia. Rev. Tamoios, São Gonçalo, (1), 16-31.

Franco, G. (2020) Coronavírus: professores falam dos desafios e vantagens de trabalhar em casa. Canal do Educador. https://educador.brasilescola.uol.com.br/noticias/coronavirus-professoresfalam-dos-desafios-e-vantagens-detrabalhar-em-casa/33270.html.

Fredriksson M., Astback J., \& Pamenius K. A. (1998) Retrospective study of 236 patients with teeth restored by carbon fiber-reinforced epoxy resin posts. J. Prosthet. Dent., [S.L], 151-157.

Freire, P. (2011) A importância do ato de ler: em três artigos que se completam. (51a ed.), Cortez.

Freire, P. (2013) Pedagogia do oprimido. (55a ed.), Paz e Terra.

Gil, A. C. (2008) Como elaborar projetos de pesquisa. (4a ed.), Atlas.

Gil, A. C. (2011). Gestão de Pessoas: Enfoque nos Papéis Profissionais. Atlas.

Hodges, C. et al. (2020). The Difference Between Emergency Remote Teaching and Online Learning. EDUCAUSE Review. https://er.educause.edu/articles/2020/3/the-differencebetween-emergency-remote-teaching-and-online-learning\#fn3.

Human Rights Watch. (2020) Eles ficam até morrer. https://Www.Hrw.Org/Pt/Report/2018/05/23/318044.

IBGE - Instituto Brasileiro de Geografia e Estatística. (2018) Pesquisa nacional por amostra de domicílios contínua: 2018 acesso à internet e a televisão e posse de telefone móvel celular para uso pessoal. https://biblioteca.ibge.gov.br/index.php/bibliotecacatalogo?view=detalhes\& id=2101631

Johns Hopkins University. (2020 Coronavirus COVID-19 Global Cases by Johns Hopkins CSSE [Internet]. Johns Hopkins University.

Kenski, V. M. (2015) Educação e internet no Brasil. Cadernos Adenaur 11(3), 133-150. http://www.researchgate.net/publication/281121751.

Kenski, V. M. (020) Cultura digital e docência no novo cenário da Educação. In: Webseminário do ForTEC, Salvador (Bahia). https://www.youtube.com/channel/ UCuCLR4FTAwIVSdDhcxYzAZQ.

Lagarto, J. R. (2013) Inovação, TIC e sala de aula. In: Cavalheiri, A.; Engerroff, S. N.; Silva, J. C. (org.). As novas tecnologias e os desafios para uma educação humanizadora, Santa Maria: Biblos.

Lemos, A. (2018) Isso (não) é muito Black Mirror: passado, presente e futuro das tecnologias de comunicação e informação. Salvador: Edufba.

Lévy, P. (1999) O que é o virtual? Editora 34.

Ludke, M., \& André, M. E. D. A. (1986) Pesquisa em educação: abordagens qualitativas. São Paulo: Pedagógica e Universitária.

Lipsithc, M. et.al. (2020). Defining The Epidemiology Of COVID-19 - Studies Needed. 2020. The New England Journal Of Medicine. https://Www.Nejm.Org/Doi/Full/10.1056/Nejmp2002125.

Martins, R. X. (2020) A COVID-19 e o fim da Educação a Distância: um ensaio. Revista de Educação a Distância, 7(1), 242-256. https://www.aunirede.org.br/revista/index. php/emrede/article/view/620.

Maurin, E., \& Mcnally, S. (2008). Vive La Revolution! Long-Term Educational Returns Of 1968 To The Angry Students. Journal of Labor Economics, 26(1), $1-33$.

Mccrindle, M. (2011) The ABC of the XYZ: understanding global generations. Sydney: UNSW Press.

Modelski, D., Giraffa, L. M. M., \& Casartelli, A. (2019) Tecnologias digitais, formação docente e práticas pedagógicas. Educação e Pesquisa, São Paulo, 45 (e180201). https://www. scielo.br/pdf/ep/v45/1517-9702-ep-45-e180201.pdf.

Moran, J. (2017) Metodologias ativas e modelos híbridos na educação. In.: YAEGASHI, Solange e outros (org.). Novas Tecnologias Digitais: Reflexões sobre mediação, aprendizagem e desenvolvimento. $\quad$ Curitiba: 23-35. http://www2.eca.usp.br/moran/wpcontent/uploads/2018/03/Metodologias_Ativas.pdf.

Mori, L., Cunha, M. B. (2020) Problematização: possibilidades para o ensino de química, Quím. nova esc., 42(2), 176-185.

Nóvoa, A. (2001) Professor se forma na escola (online). Revista Nova Escola, 142(16), 13-15.

Nóvoa, A. (2011) O regresso dos professores. Universidade de Lisboa. 
Nóvoa, A. (2020) Palestra proferida na abertura da Formação Continuada Territorial a Distância, Salvador (Bahia). https://www.youtube.com/watch?v=wxdeAxdegE.

Organização Das Nações Únicas (ONU). (2020) Who And Unicef Warn Of A Decline In Vaccinations During COVID-19. Geneva. https://Www.Who.Int/News-Room/Detail/15-07-2020-Whoand-Unicef-Warn-Of-A-Decline-In-Vaccinations-During- COVID-19.

Organização Mundial Da Saúde (OMS). (2018) Metodologia para a avaliação de oportunidades perdidas de vacinação. [S.L.]: OMS. https://Apps.Who.Int/Iris/Bitstream/Handle/10665/259201/9789248512957-Por.Pdf?Ua=1 .

Palfrey, J., Gasser, U. (2011) Nascidos na era digital: entendendo a primeira geração dos nativos digitais. Porto Alegre: Artmed.

Perrenoud, P. (2000) 10 novas competências para ensinar. Artmed.

Piopiunik, M, G Schwerdt, L Simon E L Woessman (2020), Skills, Sinalizações e Empregabilidade: Uma Investigação Experimental. European Economic Review 123: 103374.

Prensky, M. (2001) Nativos Digitais, Imigrantes Digitais. De On the Horizon, NCB University Press, 9 (5), 1-6. www.colegiongeracao.com.br/novageracao/2_intencoes/nativos.pdf.

Pretto, N., Bonilla, M. H., \& Sena, I. (2020) Educação em tempos de pandemia: reflexões sobre as implicações do isolamento físico imposto pela COVID-19. Salvador: Edição do Autor.

Ribeiro, L. R. C. (2008) Aprendizado baseado em problemas. UFSCAR; Fundação de Apoio Institucional.

Rodrigues, K. G., \& Lemos, G. A. (2019) Metodologias ativas em educação digital: possibilidades didáticas inovadoras na modalidade EAD. Ensaios Pedagógicos, Sorocaba, 3(3), 29-36. http://www.ensaiospedagogicos.ufscar.br/index.php/ENP/ article/view/156.

Rodrigues, M. L., \& Limena, M. M. C. (Orgs.). Metodologias multidimensionais em Ciências Humanas. Brasília: Líber Livros Editora, 2006.

Sales, K. M. B. (2013) Cognição em ambientes com mediação telemática uma proposta metodológica para análise cognitiva e da difusão social do conhecimento. Tese (Doutorado em Difusão do Conhecimento). Faculdade de Educação, Universidade Federal da Bahia, Salvador.

Sales, K. M. B., \& Pinheiro, T. (2018) A EaD na IPES Baianas: Desafios na Graduação e na Pós-graduação. In: SALES, Mary Valda. Tecnologias e Educação a Distância: os desafios para a Formação. Eduneb.

Salvador, C. C. et al. (1999) Psicologia da educação. Artes Médicas Sul.

Santana, C. (2019) Pedagogias das conexões: ensinar e aprender na sociedade digital blended. EmRede - Revista de Educação a Distância, 6(2), 1-19.

Santo, E. E., \& Trindade, S. D. (2020) Educação a distância e educação remota emergencial: convergências e divergências. In: Machado, D. P. Educação em tempos de COVID-19: reflexões e narrativas de pais e professores. Curitiba: Editora Dialética e Realidade.

Santos, B. S. S. (1989) Introdução a uma Ciência Pós-Moderna. (4a ed.), Graal.

Santos; E. (2019) Pesquisa-formação na cibercultura. Edufpi.

Severino, A. J. (2007) Metodologia do Trabalho Científico. Cortez.

Shinyashiki, E. (2020) Educação e as crianças da geração Z. http://www.administradores.com.br/informe-se/informativo/educacao-e-as-criancas-da-geracaoz/26948

Tarouco, L. M. R. (2019) Competências Digitais dos Professores. In: Comitê Gestor da Internet no BRASIL (CGI.br). Pesquisa sobre o uso das tecnologias de informação e comunicação nas escolas brasileiras: TIC educação 2018. São Paulo: Comitê Gestor da Internet no Brasil. https://cetic.br/media/docs/publicacoes/216410120191105/tic_edu_2018_livro_eletronico.pdf.

Thiollent, M. (1985) Metodologia da Pesquisa-Ação. Cortez.

Thornburg, D. (2010) Learning On The Holodeck: Transforming Classrooms For All Learners. http://Www.Tcse-K12.Org/Pages/Holodeck.Pdf.

Todos pela educação. (2020) Nota técnica: análise: ensino a distância na educação básica frente à pandemia da Covid-19. Todos pela Educação, abril de 2020. https://www. todospelaeducacao.org.br/_uploads/_posts/425.pdf.

Tomazinho, P. Ensino Remoto Emergencial: a oportunidade da escola criar, experimentar, inovar e se reinventar. Medium. https://medium.com/@ paulotomazinho/ ensino-remoto-emergencial-a-oportunidade-da-escola-criar-experimentar-inovar-e-se-reinventar6667ba55dacc

Tori, R. (2017) Educação sem distância: as tecnologias interativas na redução de distâncias em ensino e aprendizagem. 2. ed., São Paulo: Artesanato Educacional.

Uneso - Organização das Nações Unidas para a Educação, a Ciência e a Cultura. (2020) COVID-19: 10 recomendações para planejar soluções de aprendizagem à distância. https://pt.unesco.org/news/covid-19-10-recomendacoes-planejar-solucoes-aprendizagemdistancia.

Unesco - Organização das Nações Unidas para a Educação, a Ciência e a Cultura. (2020) Education: From Disruption To Recovery: COVID-19 Impact On Education. https://En.Unesco.Org/ COVID-19/Educationresponse.

Viner, R. M. et al. (2020) School closure and management practices during coronavirus outbreaks including COVID-19: a rapid systematic review. Lancet Child Adolesc Heal, 4(5) 397-404. 
Research, Society and Development, v. 10, n. 15, e519101523366, 2021

(CC BY 4.0) | ISSN 2525-3409 | DOI: http://dx.doi.org/10.33448/rsd-v10i15.23366

Wellcome. (2020) Sharing Research Data And Findings Relevant To The Novel Coronavirus (COVID-19) Outbreak. Organisation For Economic CoOperation And Development. https://Wellcome.Org/Press-Release/Sharing-Research-Data-And-Findingsrelevant-Novel-Coronavirus-Ncov-Outbreak.

WHO - World Health Organization. (2020) Covid-19 quick links. https://www.who.int/ 